\title{
Do corpo, da Educação Física e das muitas histórias
}

Carmen Lúcia Soares ${ }^{2}$

\begin{abstract}
Resumo: Este artigo concebe o Colégio Brasileiro de Ciências do Esporte (CBCE) como um lugar possível da memória que revela, em sua curta existência - 25 anos - a emergência e a visibilidade das muitas histórias da Educação Física/Ciências do Esporte no Brasil a partir da configuração de novos problemas, objetos e abordagens.

Palavras-chave: Corpo, CBCE, História da Educação Física.
\end{abstract}

Este tema remete às muitas e múltiplas idéias de passado, aos muitos passados que podem ser construídos no presente com o conhecimento, sempre em transformação, deste outro tempo, desta outra sensibilidade que buscamos captar. ${ }^{3}$ As idéias de passado e de como pensar o passado são múltiplas e também na literatura podemos encontrar ecos. O escritor ucraniano Joseph Conrad, ${ }^{4}$ por exemplo, diz-nos que

[...] quando começamos a meditar sobre o significado de nosso passado, ele parece preencher o mundo inteiro com sua profundidade e magnitude. [...] $O$ efeito de perspectiva da memória é fazer com que as coisas projetem um reflexo amplo, porque aquilo que é essencial sobressai, isolado de sua paisagem de insig-nificantes fatos diários, os quais desbotam naturalmente até sumirem de nossas mentes.

Mas o que é essencial para aquele que rememora?

Talvez o CBCE seja mesmo, numa época de esquecimento deliberado, um lugar possível da memória; um lugar que permite pensar, neste curto recorte de tempo de sua existência -25

\footnotetext{
1 Texto apresentado originalmente na Mesa Redonda intitulada "O CBCE e a história da Educação Física brasileira", durante a realização do XIII CONBRACE, na cidade mineira de Caxambu, de 11 a 19 de setembro de 2003

2 Professora Doutorada Faculdade de Educação-UNICAMP/SR

3 Esta compreensão de história é desenvolvida por Marc Bloch no livro Introdução à História.

4Estas idéias estão em seu romance Linha de sombra, escrito em 1920 (p. 7).
}

Movimento Porto Alegre, v.9, n. 3, p.125-147, set./dez. de 2003 
anos -, a emergência e a visibilidade das muitas histórias da Educação Física/Ciências do Esporte (EF/CE) a partir da configuração de novos problemas, abordagens e objetos. E talvez aqui, as palavras de Jean Starobinski ${ }^{5}$ nos ajudem a pensar esta configuração:

[...] admitamos que a escolha de um objeto de estudo não é inocente, mas que impõe já uma interpretação prévia, inspirada por nosso interesse atual Reconheçamos que não se trata de um puro dado, mas de um fragmento do universo que se delimita por nossa maneira de olhar. Confessemos também que a linguagem em que assinalamos um dado já é a linguagem em que ulteriormente o interpretaremos.

Num certo sentido, neste breve período de existência, o CBCE vai aprendendo e ensinando a recusar primazias estabelecidas, a complexificar problemáticas consagradas, desnaturalizando-as e remetendo-as ao debate em todas as suas possíveis abordagens. E desnaturalizar é uma libertação, porque significa saber que nada foi sempre de um mesmo modo; desnaturalizar é historicizar.

Pode-se afirmar, por exemplo, que nos seus múltiplos registros, ${ }^{7}$ encontramos uma história das transformações da EF/ CE no Brasil, ao mesmo tempo que transformações do próprio $\mathrm{CBCE}$.

Como afirmam Goellner, Mello e Paiva, ${ }^{8}$ o[...]" CBCE não teve um desenvolvimento harmônico, linear, 'evolutivo', mas foi

5 Jean Starobinski, "A literatura", em Jacques Le Goff e Pierre Nora, História: novas abordagens (p. 132).

6 Estas afirmações foram feitas pela historiadora Luiza Margareth Rago no âmbito de uma palestra sobre o tema "Subjetividade e experiência na pesquisa histórica", proferida junto ao programa de pós-graduação em educação da Faculdade de Educação-UNICAMR em atividade programada de pesquisa por mim coordenada no 1 - semestre de 2003.

7 Ver a respeito o excelente trabalho de Fernanda Simone Paiva, Educação Física/ Ciências do Esporte: resgate e perspectivas na luta dos sentidos dentro do CBCE, Dissertação (Mestrado em Educação Física), Rio de Janeiro, Universidade Gama Filho 1993, trabalho que posteriormente foi publicado na forma de livro com o seguinte título: Ciência e poder simbólico no Colégio Brasileiro de Ciências do Esporte, Vitória, CEFD/UFES, 1994. Neste trabalho encontramos registrada, por exemplo, a dificuldade que esta pesquisadora viveu para reunir documentos e fontes relativas ao CBCE como instituição. Há uma profusão de trabalhos sobre o CBCE e não é minha intenção nos limites desta mesa fazer um levantamento a este respeito.

8 Silvana Vilodre Goellner, Victor Andrade de Melo e Fernanda Simone Paiva, "Revista Brasileira de Ciências do Esporte: bibliografia e perfil", Revista Brasileira de Ciências do Esporte, número especial - 20 anos do CBCE, set. 1998, p. 73. 
cunhado dentro das lutas simbólicas próprias do campo científico".

Em sua história tão recente, já é possível reconhecer permanências e mudanças dos objetos pesquisados, daqueles que são (literalmente) abandonados e de outros que tomam o seu lugar a partir de outras abordagens e de novas problemáticas que suscitam. O CBCE talvez testemunhe, em seus ditos e em seus silêncios, em sua continuidade e rupturas, receios e certezas de cada época, e revele permanências e mudanças no modo de conceber, atuar e pesquisar a $\mathrm{EF} / \mathrm{CE}$... até mesmo, é possível dizer, de ousar reconstruí-las.

Talvez seja o CBCE, já num contexto de emergência da pósgraduação e da pesquisa em EF no Brasil, particularmente a partir dos anos 80, o lugar mais visível (democratizado?) de de bates que se propõem a desnaturalizar a EF/CE, numa clara ten tativa, inicialmente tímida, de afirmar a existência das múlti plas camadas de memória que as constituem; de como um mes mo objeto se vai transformando e se mostrando múltiplo; de como novos objetos, problemas, abordagens e interpretações se vão afirmando como legítimos ao lado do que estava consagrado como único e de como este movimento, permeado por crises e tensões, redesenha a própria existência do CBCE... de como a redemocratização do país redesenha as forças em jogo e os próprios objetos a serem estudados.

No CBCE podemos identificar claramente como o corpo e suas múltiplas linguagens vão sendo desnaturalizados e se vão transformando em objetos capazes de esclarecer um mundo, conforme nos ensina o historiador francês Georges Vigarello.

\section{Dos lugares de visibilidade das transformações do CBCE: os anais dos CONBRACEs como fonte ${ }^{10}$}

Os temas oficiais ${ }^{11}$ dos CONBRACEs, em sua formulação aparentemente simples, já sugerem inflexões importantes e ates-

\footnotetext{
9 Ver por exemplo Georges Vigarello, "A história e os modelos do corpo", Revista Pro- Posições, Faculdade de Educação, UNICAMR Campinas/SR vol.14, n.2(41), mar. 1990, pp.21-29.

10 Para a elaboração deste texto foram consultados os Anais dos 12 Congressos Brasileiros de Ciências do Esporte realizados de 1979 até 2001.

11 Os CONBRACEs tiveram os seguintes temas: I "A criança brasileira e a atividade
}

Movimento Porto Alegre, v.9, n. 3, p.125-147, set./dez. de 2003 
tam tanto transformações quanto o surgimento de novos objetos, abordagens e problemas. Do mesmo modo, a própria estrutura organizacional destes eventos é também testemunho significativo desta afirmação.

$\mathrm{O} \mathrm{CBCE}$ nasce num Brasil endurecido e profundamente marcado pela ditadura militar dos anos 70, período em que é possível constatar a emergência e a proliferação discursiva das vantagens e da importância de espaços de descanso e de diversão do trabalhador, uma preocupação mais acentuada com os usos do tempo livre e deste tempo voltado para a prática de atividades físicas e esportivas; período que promove uma cultura esportiva, um modo esportivo de ser e cultua também um certo tipo de descontração e um certo tipo de corpo, saudável e produtivo. ${ }^{12}$

A década de 70 é aquela que gera o Plano Nacional de Educação Física (PNED), ${ }^{13}$ e é também a década das campanhas em prol da saúde e do lazer pela atividade física orientada, como a "Esporte para Todos" (EPT) e a "Mexa-se". Estas campanhas traduzem em grande medida a ambição dos governos militares de abrir espaço, dar visibilidade e estimular a existência de corpos velozes, úteis e sadios. Num certo sentido, estas campanhas "atualizam" aquelas feitas por médicos e educadores nos anos 20 do século XX, quando o tempo fora da fábrica ou da escola passou a ser uma preocupação. Também lá nos anos 20, como ali nos anos 70, o esporte e os exercícios físicos, re-significados pela sensibilidade de cada época, possuíam semelhantes vantagens

física"- São Caetano do Sul/SR 1979; II "Esporte no Brasir-Londrina/PR, 1981; III "Treinamento esportivo"- Guarulhos/SR 1983; IV "As ciências do esporte na Nova República"- Poços de Caldas/MG, 1985; V "A criança e o esporte no Brasil"-Olinda/PE, 1987; VI "Esporte e mudança na América Latina"- Brasília, 1989; VII "Produção e veiculação do conhecimento na educação física, esporte e lazer no Brasil: análisee perspectivas", 1991; VI11 "Que ciência é esta? Memória e tendências"-Belém/PA, 1993; IX "Interdisciplinaridade, ciência e pedagogia"-Vitória/ES, 1995; X "Renovações, modismos e interesses"- Goiânia/GO, 1997; XI "Educação Física/ Ciências do Esporte: intervenção e conhecimento"-Florianópolis/SC, 1999; XII "Sociedade, ciência e ética: desafios para a Educação Física"- Caxambu/MG. O último, que não foi objeto de análise desta mesa, foi o de n. XIII e teve como tema "25 anos de história: o percurso do CBCE na Educação Física Brasileira", realizado em Caxambu/MG, 2003.

12 Ver por exemplo Denise Sant'Anna, O prazer justificado: história e lazer (São Paulo, 1961/1979),São Paulo, Marco Zero/CNPq, 1992

$13 \mathrm{~A}$ respeito de políticas públicas para a Educação Física e Esporte no Brasil vera pesquisa de Meily A. Linhales. A trajetória política do esporte no Brasil: interesses envolvidos, setores excluídos. Belo Horizonte: FAFICH/UFMG. Dissertação 
"educativas". Cabe lembrar que no Brasil do PNED, por exemplo, o desporto é definido em lei (n. 6.251, de 8/10/75) como "[...]um dos mais valiosos elementos de apoio à formação do homem e de coesão nacional e social, podendo solucionar problemas gerados pela moderna sociedade industriar".

Nos anos 20, médicos e educadores viam a EF e os esportes como importantes fatores de higiene pessoal e de coesão social e os campos de recreação e de esportes como possibilidade concreta de saneamento do meio. EF e esportes eram "problemas de saúde pública $^{\prime \prime 14}$ e vistos como uma necessidade. No caso específico da $\mathrm{EF},{ }^{15}$ afirmavam os médicos que ela deveria ocupar lugar de evidência porque, quando bem dirigida, fortifica e disciplina o caráter e o corpo, ao mesmo tempo em que dirige a população para diversões sãs, constituindo-se, portanto, em fonte de profilaxia reaf $f^{6}(\mathrm{~V}$ Congresso Brasileiro de Hygiene, Recife, 1929).

A EF e os esportes praticados em parques transformavam-se, assim, em saneadores do meio; portanto, estes espaços deveriam

[...] ser distribuídos pelos núcleos da população, [pois] garantem não só permanente e efetiva atuação, como podem trazer a melhor cooperação nas campanhas sanitárias, pelo atrativo que exercem principalmente sobre as crianças e a mocidade, que para freqüentá-los submeter-se-iam facilmente às exigências de assistência sanitária. ${ }^{1}$

Os profissionais que dela se ocupam são, nesse momento (anos 20 do século XX), representados como arautos da saúde, vendedores de força e beleza, robustez e vigor. Seria esta uma permanência no tempo histórico?

O CBCE, em suas origens, demarca já um momento bem definido da vida da entidade, revelando permanências e rupturas, receios, crenças e certezas, e traz consigo as marcas muito particulares que foram lentamente construídas pelos conhecimentos de natureza científica desde fins do século XVIII, mas, sobretudo, do século XIX. $\mathrm{O}$ conteúdo dos seus registros configura e permite apreender um modo específico de olhar o corpo e a educação do corpo a partir de parâmetros fornecidos pela ciên-

\footnotetext{
14 Congresso Brasileiro de Hygiene, 5, Recife, 1929, Annaes, p.133.

15 Ver por exemplo o trabalho de Tarcísio Mauro Vago, Cultura escolar e cultivo de corpos, 2002.

16 Waldomiro de Oliveira, Congresso Brasileiro de Higiene, 5, Recife, 1929, Annaes, p.140.

17 Congresso Brasileiro de Hygiene, 5, Recife, 1929, Annaes, p.140.
}

Movimento Porto Alegre, v.9, n. 3, p.125-147, set./dez. de 2003 
cia desse período, guardadas as devidas proporções de tempo e de sínteses científicas possíveis.

Os primeiros seis anos e os três primeiros CONBRACEs podem ser lidos como linha de continuidade dessa compreensão de educação que se constrói lentamente no Ocidente, e que vai, paulatinamente, ocupando um lugar central e, deste modo, desenvolvendo inúmeras pedagogias que, conforme afirma Vigarello, [...]"são portadoras de preceitos que dão ao corpo uma forma e o esquadrinham para submetê-lo à normas, de um modo muito mais seguro ainda que o pensamento". ${ }^{18}$ Os exercícios físicos e mais tarde o esporte podem, assim, ser compreendidos como pedagogias voltadas à educação do corpo, sua preservação e manutenção da saúde individual e social.

A idéia de que o corpo em sua exterioridade traduz uma posição moral interna tem sido largamente tratada no Ocidente, mais acentuadamente a partir do século XIX, pelos discursos médico, jurídico, pedagógico e literário. ${ }^{19}$ Esse é um tempo de especialização de discursos sobre a educação do corpo voltados para a construção de uma retidão de posturas e comportamentos. Era dever da ciência encontrar soluções para educar o corpo adequadamente, endireitá-lo. É adequado recordar quais eram as referências que tornavam os discursos sobre o corpo cada vez mais especializados e que embasaram essa cruzada físico-mo-ral. Eram os tratados de higiene, fisiologia, anatomia e mecânica, acrescidos de uma boa dose de convencimento sobre a necessidade de pôr o corpo em movimento como pressuposto fundamental de um bem-estar geral.

Há, nesse momento, um claro desejo de que o indivíduo aprenda a agenciar suas próprias forças para lograr a obtenção do físico requerido e da sociedade ordenada e civilizada.

É necessário registrar ainda que, ao final do século XIX e início do século $\mathrm{XX}$, as preocupações em torno do corpo e de sua funcionalidade estiveram diretamente ligadas aos problemas

18 Georges Vigarello, Les corps redressé, 1978, p. 9.

19 Estas idéias estão desenvolvidas mais amplamente no artigo intitulado "Pedagogia dos corpos retos: das morfologias disformes às carnes alinhadas", escrito em parceria com Alex Branco Fraga e publicado na Revista Pro-Posições, vol. 14, n.2(41), pp. 77-90, 2003. Ver ainda os livros de minha autoria "Educação Física'. raízes européias e Brasil", 1994 e "Imagens da educação no corpo: estudo a partir da ginástica francesa no século XIX", além do artigo "Notas sobre a educação no corpo" In Educar em Revista, n. 16,2002, "dossiê corporalidade educação", pp.43- 
Do corpo, da Educação Física...

relativos à degeneração física e moral das populações. Essas preoocupações não eram novas, o novo era a forma de investimento sobre os corpos. É o caso da anatomia, o "olho mágico" capaz de perscrutar, nomear e tornar visíveis os órgãos debaixo da pele. É a anotomia que vai precisar os desenhos e, assim, criar uma objetividade do olhar.

Elabora-se com requinte um modelo novo de corpo útil e uma tecnologia do orgânico conceitualiza-se com a finalidade de fazer crescer a chamada eficácia funcional. Os exercícios físicos e, mais especificamente, a ginástica, passam a ser percebidos como capazes de revelar, a partir de sua apurada sistematização, uma visão totalmente nova do movimento corporal, e tam bém de sua aplicação no trabalho.

A imagem, como resultado técnico da utilização de diferen tes aparelhos, torna-se parte integrante das explicações e constitutiva dos discursos sobre o movimento humano, este novo objeto da ciência experimental que potencializa o rigoroso esquadrinhamento do corpo, realizado ao longo de todo o século

O médico e fisiologista Etienne-Jules Marey (1830-1904), juntamente com seu auxiliar, o biólogo Georges Demeny, reali zaram os estudos mais precisos e rigorosos, nos limites dados pelo desenvolvimento do conhecimento científico de seu tem po sobre a locomoção humana, o vôo dos pássaros, o galope do cavalo na água que corre. Esses dois cientistas criaram os processos precisos do método gráfico, cronográfico e cinematográfico para a compreensão do movimento humano com base em estudo do movimento de aves e animais. ${ }^{20}$

Os experimentos cronofotográficos realizados por esses cien tista passaram a funcionar também como uma espécie de "olho mágico" da ciência sobre os corpos, porém não se tratava ape nas de dar visibilidade aos órgãos internos, algo já conquistado pela anatomia, mas sim de desvendar e registrar os segredos do corpo em deslocamento. Eficiência dos gestos, precisão e econo mia de forças eram demandas das novas configurações dos es paços de convivência social e do mundo do trabalho.

20 Ver a respeito do trabalho de Vinícius Terra, Pedaços do tempo, gestos partidos: Memórias do corpo em movimento na fotografia de Etienne-Jules Marey. 2002. Dissertação de Mestrado em Educação) - Faculdade de Educação, UNICAMR Campinas/SP

Movimento Porto Alegre, v.9, n. 3, p.125-147, set./dez. de 2003 
As Obras Completas de Rui Barbosa, por exemplo, contêm extensas análises sobre as vantagens ou desvantagens dos métodos europeus de ginástica e constituem uma fonte rica em detalhes ainda a serem explorados pela história da EF no Brasil.

Do conjunto de profissionais que tiveram um papel determinante na construção e ordenação da hoje denominada $\mathrm{EF}$ ao longo de todo o século XIX e princípio do século XX, quer seja na Europa, quer seja no Brasil, destacam-se os médicos. Seria esta mais uma permanência histórica?

Assim, parece que os três primeiros CONBRACEs são fortemente marcados por esta visão e compreensão de ciência forjadas no século XIX; de uma busca que se fez nesse século de legitimação dos exercícios físicos como práticas informadas e respaldadas pelo pensamento científico, evidentemente, completamente re-significadas pelas condições de desenvolvimento do pensamento científico do presente e, sobretudo, pela tecnologia, pelos instrumentos e materiais que constituem as condições de construção e de trabalho nos laboratórios de análise do exercício dos anos 70 e 80 no Brasil, assim como de seus objetivos.

O historiador Marc Bloch pergunta: julgar ou compreender? Énos sempre mais fácil julgar, mas ele nos ensina:

Quem difere de nós -estrangeiro, adversário político-, passa, quase necessariamente, por mau [...]. A história é uma vasta experiência da diversidade humana, um longo encontro dos homens. A vida, como a ciência, tem tudo a ganhar se o encontro for fraternal ${ }^{21}$

Pensemos então, no tema do primeiro CONBRACE: "A crian ça e a atividade física"; seria possível para a $\mathrm{EF} / \mathrm{CE}$ daquele momento tratar este tema com o alcance, abrangência e/profun didade que ele já vinha recebendo de outras esferas ainda pou co visíveis da sociedade brasileira? $\mathrm{O}$ trabalho e a prostituição infantil estavam lá; os altos índices de evasão e repetência escol ar estavam lá; a miséria secular da sociedade brasileira nunca deixou de existir e a criança brasileira era também expressão deste quadro.

Talvez o tema da criança, naquele evento, estresse mais sintonizado com a política educacional do período, houve um

21 Marc Bloch, op. cit, p. 126.

Movimento Porto Alegre, v.9, n. 3, p.125-147, set./dez. de 2003 
painel que discutiu a EF permanente, as curvas de desenvolvimento motor de escolares, a criança e a atividade física, assim como também foi abordado um tema da antropometria: as dobras cutâneas de escolares, e houve ainda uma apresentação concernente ao tema do currículo de escolas de EF no Brasil.

Num olhar mais alargado para esse período, é possível encontrar um tema que não só motivava vários estudos mas, sobretudo, políticas públicas para o setor educacional: a psicomotricidade, considerada, na época, o grande avanço na EF escolar, também chamada de EF infantil; a psicomotricidade assim como a psicocinética de Jean Le Bouch freqüentavam os gabinetes das secretarias de educação e de esportes em suas coordenações de EF para o escolar e produziam um pensamento acerca da EF para a infância. ${ }^{22}$ Estaria o CBCE em sintonia com políticas educacionais do período? Com os programas de ensino de EF de estados e municípios que naquele momento elegiam a psicomotricidade ${ }^{23}$ como conteúdo da EF para o escolar?

Seria esta outra permanência na história da EF no Brasil?

Esta concepção de EF para a infância estava em conformidade com a teoria educacional em voga naquele momento: o chamado tecnicismo. Para esta concepção de Educação, a criança era vista como passível de uma educação motora, cognitiva e afetivoemocional; à então recente EF escolar destinada a esta "faixa etária" caberia ocupar-se do domínio motor, que sempre deveria estar vinculado aos outros "domínios", o cognitivo e o afetivo-emocional. Deste modo a educação trataria de um desenvolvimento integral: biopsico-social.

Esses discursos da EF para o escolar ou para a infância eram também expressão de um outro fenômeno extremamente forte na educação do período: a medicalização da escola e, sobretudo, da infância. No âmbito específico da EF, os exames médicos para a sua prática constituíam-se em obrigatoriedade fornecida no plano legal pelo Decreto Federal n. 69. 450/71 e a presença do médico na escola, uma necessidade imperiosa; mais amplamente,

22 Sobre a Educação Física escolar e a ditadura militar ver Marcus Aurélio Taborda de Oliveira, Educação Física escolar e ditadura militar no Brasil (1968-1984): entre a adesão e a resistência, 2003.

23 Integrei grupos de trabalho da Prefeitura Municipal de Curitiba entre os anos de 1979 e 1983, grupos que elaboraram um programa de Educação Física para as séries iniciais do antigo primeiro grau baseado na psicomotricidade.

Movimento Porto Alegre, v.9, n. 3, p.125-147, set./dez. de 2003 
as políticas para o setor desenhavam a possibilidade de se ter na escola não apenas a medicina, mas a medicina esportiva...

$\mathrm{O}$ médico e a forte presença da medicina nos rumos da EF escolar não era um tema novo. Nos anos 20 do século XX, os médicos não só se faziam presentes na escola, como eram aqueles que prescreviam os exercicios fisicos. A autoridade de seu saber evitaria que se cometessem abusos tanto na dosagem dos exercícios, quanto em sua adequação às distintas faixas etárias das crianças. Naquele momento configurou-se um tipo de controle do médico sobre o conteúdo a ser ensinado e sobre aquele que ensina os exercícios físicos na escola. ${ }^{24}$

\section{Seria esta outra permanência histórica?}

Nesse quadro referencial da pedagogia tecnicista, em sua aliança com a EF escolar dos anos 70, estão também presentes os chamados objetivos operacionais, e em sua formulação, a avaliação das habilidades motoras, dos testes motores, entre outros aspectos pedagógicos que merecem maior análise.

A avaliação das habilidades e capacidades materializava, deste modo, uma compreensão de EF escolar sintonizada com as teorias de educação do momento, nas quais a importância a ela atribuída estava vinculada à sua capacidade de melhorar o desempenho cognitivo; a EF estava instrumentalizada para auxiliar a matemática, a língua portuguesa, os estudos sociais. Ela servia para..., o seu conteúdo era, por um lado, meramente instrumental e funcional para a vida escolar e, por outro, funcional para a futura vida esportiva. Os seus conteúdos clássicos transformaram-se em "meios" para desenvolver lateralidade, coordenação fina, orientação espacial etc.

"Esporte no Brasil" e "Treinamento esportivo" foram os temas oficiais dos congressos subseqüentes, respectivamente em 1981, em Londrina, e 1983, em Guarulhos. Nestes dois eventos subseqüentes emergem, mesmo que ainda de forma tímida, novas abordagens, problemas e objetos, e dos 123 temas livres apresentados, 26 possuíam uma abordagem dada pelas ciências humanas.

O segundo congresso, cujo tema foi "Esporte no Brasil", revela algo pouco comum no âmbito do CBCE e de seus congres24 Ver a respeito os Anais do Congresso Brasileiro de Hygiene, 3, realizado em São Paulo
em 1926, p. 868 . 
sos oficiais bianuais: ele foi "apoiado" por uma empresa privada de material esportivo, a Adidas. Esta aliança pode revelar muitas faces e não é meu intuito discuti-las no âmbito desta exposição.

A leitura do editorial dos anais deste evento, escrito pela Adidas, revela uma determinada concepção de esporte que é ainda hoje presente em muitos fóruns da $\mathrm{EF} / \mathrm{CE}$, de políticas públicas para o setor e, sobretudo, da mídia. Assim, no âmbito daquele CONBRACE o esporte ainda não aparece como objeto de estudo das ciências humanas; aparece ainda livre das contaminações próprias da vida em sociedade, dos problemas sociais, dos problemas específicos vividos pelas mulheres no âmbito esportivo e, sobretudo, da política.

Embora o esporte já fosse há décadas um legítimo objeto de estudos das ciências humanas, um objeto capaz de explicar sociedades, culturas e relações de poder, foi assim definido naquele editorial. Vejamos este trecho:

[...] lembramos sempre que através da prática do esporte os homens de todas as partes do mundo se encontram, se harmonizam, se entendem e fazem-se amigos. Também a competição esportiva, imune às influências de raças, credos religiosos ou ideológicos, une e aproxima os povos, não só do nosso país, mas de todo o mundo.

Não seria esta outra permanência histórica?

Georges Vigarello vai dizer que

[...]"em um mundo sem transcendência e sem deuses, o esporte seria um dos últimos lugares onde se poderia falar em ideal ou, em outras palavras, se falar do sagrado. Sua própria visibilidade, seu simplismo talvez, sua vontade obscura de constituir um mundo separado e "preservado"o transforma também em um dos lugares de uma hipocrisia rasteira, servil senão de uma evidente vulnerabilidade. Mais que outras práticas, o esporte revela nossas sociedades. ${ }^{26}$

Mas para tal é necessário indagar sobre esta prática, não considerar natural o que ela apresenta em suas múltiplas dimensões, muitas das quais não querem ser vistas.

25 "Editorial", Revista Brasileira de Ciências do Esporte, Suplemento n. 1, set. 1981.

26 "[...] Dans um monde sans transcendence et sans dieux, le sport serait un des derniers lieux exprimant de Tidéal, voire du sacré. Sa visibilité même, son simplisme sans doute, sa volonté obscure de constituer un monde séparé et "preserve" en font aussi um des lieux d'une hypocrisie rampante sinon d'une évidence vulnérabilité. Plus que d'autres pratiques, le sport révèle nos sociétés.[...]". Georges Vigarello, Du jeu ancien au show sportif: la naissance d'un mythe, 2002,p.10. 
Veja-se, por exemplo, e ainda no âmbito deste evento, uma sofisticada imagem de mulher feita em estúdio, "vestida" de "Adidas", pernas em evidência, seios seminus, maquiagem pesada, imagem que foi veiculada na contracapa da revista dos anais desse evento. Sem qualquer dúvida, esta imagem evidencia o corpo feminino como um objeto de propaganda. Podemos indagar pela sensibilidade daquela época; pela naturalidade em que o corpo feminino serviu de propaganda para um "uniforme" esportivo dessa empresa e foi veiculado numa revista científica da área da EF/CE. Como foi possível que, naquele momento, tudo aquilo parecesse natural, normal, harmônico? Como foi possível ao $\mathrm{CBCE}$ se colocar tão à margem de toda a sociedade brasileira num momento, 1981, no qual o movimento de mulheres já se fazia ouvir em inúmeros fóruns, em inúmeros eventos, em partidos políticos que iniciavam sua reestruturação? Em revistas de circulação nacional? Um momento em que já havia estudos que tocavam problemáticas afetas às mulheres na pesquisa em ciências humanas no Brasil? ${ }^{27}$ Esta imagem, como concentração de muitas outras, como uma janela que permite ver o mundo, poderia indicar a necessidade de transformar o tema da mulher como central para um CONBRACE, e creio ser um desafio para nós realizá-lo um dia.

Talvez aqui não haja nada mais adequado que a leitura do livro de Silvana Goellner ${ }^{28}$ cujo conteúdo indica uma profusão de sentidos para pensar que "[...] bela, maternal e feminina [são] imagens afirmativas que permitem compreender que o corpo da mulher, ao mesmo tempo que é seu, não lhe pertence".

Mas, continuemos nosso percurso para buscar "conhecer" esse passado, interpretá-lo a partir dos vestígios que foram destruídos e/ou preservados, enfrentando os desafios próprios àqueles que buscam mais compreender do que julgar, aqueles que buscam captar não apenas as permanências ou rupturas mas, também, os contornos que são dados pelo tempo naquilo que se

\footnotetext{
27 Estudos sobre mulheres, sobre problemáticas específicas das mulheres e um forte movimento de mulheres ocorre no Brasil neste período; os estudos de gênero, contudo, só se farão presentes no país a partir dos anos 90; ver a respeito autores como Guacira Lopes Louro, Luzia Margareth Rago entre outros. Na EF ver, por exemplo, o trabalho pioneiro de Eustáquia S. de Souza. Meninos a Marcha, Meninas a Sombra: a história da Educação Física em Belo Horizonte- 1897-1994. Tese (Doutorado em Educação)- Faculdade de Educação, UNICAMP Campinas.

28 Silvana Vilodre Goellner, Bela, materna/e feminina: imagens da mulher na Revista Educação Physica. ljuí: Unijuí, 2003, p.144.
} 
busca "compreender", as condições daquele que escreve a história...sua capacidade de pensar e de dar significado ao que veio antes e ao que veio depois do que se deseja contar.

Os três primeiros CONBRACEs revelam que o corpo, o esporte, o exercício físico, a EF do escolar (assim ela era chamada) ainda não são, de uma forma equilibrada, objetos passíveis de serem tratados também pelas ciências humanas; eles ainda não revelam sociedades... Nesses primeiros eventos, é possível encontrar uma tímida presença das ciências humanas na abordagem desses mesmos objetos, assim como da relação da EF/CE com a sociedade.

Nesses seis primeiros anos e nesses três primeiros congressos ainda ecoam vozes de um passado, re-significados naquele presente pela emergência da medicina do esporte, dos laboratórios de análise do exercício re-elaborados com os recursos científicos e tecnológicos do presente como lugares em que se forjam verdades a respeito da EF/CE. Há ainda, naquele momento, uma coáfiança na formulação de hipóteses e na configuração de problemáticas de pesquisa possíveis pelo aporte das ciências naturais, na crença de que haverá respostas para os problemas postos pela $\mathrm{EF} / \mathrm{CE}$ e, ao mesmo tempo, que este aporte garantirá a entrada segura da EF no chamado universo científico.

Num certo sentido, é possível dizer que o $\mathrm{CBCE}$ desses primeiros anos e os seus três primeiros congressos são tributários do pensamento científico do século XIX, sobretudo daquele da segunda metade, momento de ascensão dos laboratórios de análise do exercício, de parte significativa de médicos que, em aliança com educadores, políticos e outros profissionais, buscam legitimidade científica para a então denominada Ginástica, e assistem, não sem tensões e sem recusas, ao surgimento do esporte como um fenômeno avassalador.

É interessante o que vai afirmar o músico Jacques Dalcroze em 1920 acerca da "esportivização" e da importância cada vez mais alargada da higiene nos rumos da Ginástica; diz-nos ele: "[...] Se a educação é essencialmente esportiva, ela excederá seu objetivo e criará gerações destituídas de sensibilidade". ${ }^{29}$

Uma leitura das origens do CBCE pelos anais de seus CONBRACEs revela verdades dessa época, assinala receios e

29 Emille Jeacques Dalcroze, Le rythme, la musique et 1'éducation, 1920.

Movimento Porto Alegre, v.9, n. 3, p.125-147, set./dez. de 2003 
ambições, crenças e valores. Não seria a entrada das ciências humanas no âmbito da entidade uma ameaça ao modelo hegemônico de se fazer pesquisa, uma vez que trazia em seus princípios e referenciais a dúvida e não mais a certeza? Trazia verdades, no plural, e não mais uma verdade? Trazia o desconforto da contradição e, sobretudo, da crítica?

As origens do CBCE podem configurá-lo, na sua importância para a história da EF no Brasil, como o resultado possível de um passado de certezas que, a partir de alianças entre médicos, pedagogos e cientistas, ousou construir legitimidades para o exercício físico, para a depois denominada $\mathrm{EF}$. Em seus primórdios, o $\mathrm{CBCE}$ não mudou nem os objetos, nem a abordagem; incorporou os conhecimentos e a tecnologia do presente, as técnicas de pesquisa, os materiais...seguiu o seu caminho guiado pelas mãos das certezas dadas pelo modo de se fazer e de se entender ciência. Mais certezas do que dúvidas habitam este $\mathrm{CBCE}$ em suas origens, e seus primeiros congressos são um testemunho destas afirmações, sobretudo se estabelecemos um diálogo com os debates da sociedade em geral e mesmo de outras sociedades científicas e literárias que emergiam naquele momento.

\section{Um outro momento, uma outra sensibilidade: $\mathrm{O}$ CBCE e os CONBRACEs dos anos 80, 90 e 2000... Rupturas?}

Houve nesse momento uma tentativa de problematizar a $\mathrm{EF} / \mathrm{CE}$, exercer a crítica, não mais aceitar como naturais os cânones estabelecidos sobre esporte, ou seja, de ser ele esta atividade "separada" e "preservada" da sociedade, conforme nos fala Vigarello, assim como dos benefícios da chamada atividade física e sua relação intrínseca com a saúde.

Havia muitas faces a serem exploradas pela pesquisa em EF/CE; as ciências humanas poderiam fornecer bases e, assim, re-significar problemas, abordagens e criar novos objetos. $\mathrm{E}$ as dificuldades para se criar esta base eram imensas, por inúmeras razões. 
O movimento da contracultura, e aquele da militância de esquerda, por motivos distintos, ganhavam sempre um enfoque depreciativo por parte da cultura oficial e eram sempre associados às imagens de degeneração ou da loucura.

Idéias que ousassem estabelecer um diálogo e que apresentassem outras possibilidades de olhar para um problema, ou de pensar outras abordagens, eram quase sempre desqualificadas, aliás uma estratégia razoavelmente bem-sucedida naquele momento.

Em meio às inúmeras e múltiplas dificuldades, a metade dos anos 80 assinala que os objetos classicamente pesquisados no âmbito da $\mathrm{EF} / \mathrm{CE}$ possuem múltiplas possibilidades de abordagem, constituem múltiplas problemáticas...são objetos históricos.

A tolerância em relação às ciências humanas no $\mathrm{CBCE}$ e em seus congressos marca, naquele momento, um caminho sem volta, evidentemente não linear e não sem conflitos.

Os CONBRACEs realizados a partir de 1985 atestam, nitidamente, uma transformação dos seus temas oficiais e revelam, finalmente, uma aproximação da $\mathrm{EF} / \mathrm{CE}$ com concepções emergentes na sociedade... revelam a emergência de abordagens construídas pelas ciências humanas para a pesquisa em EF/CE. É evidente que esta nítida transformação não ocorreu sem tensões: talvez os anos 80 sejam mesmo, para o CBCE, um período que vai, com suas imensas contradições e seus argumentos ainda em construção, revelar muito do que já se fazia durante o período anterior e que não possuía ainda visibilidade ou legitimidade.

Do ponto de vista exclusivo das questões acadêmicas, não quero, contudo, afirmar que as abordagens trazidas pelas ciências humanas sejam, em sua totalidade, positivas e livres de críticas. Quero afirmar apenas a sua importância para a pesquisa em $\mathrm{EF} / \mathrm{CE}$ e para o próprio CBCE que, então, passa a indagar-se sobre o lugar da EF/CE na sociedade brasileira, sobre as parcerias, sobre o seu papel na definição de políticas públicas para a área.

"As ciências do esporte na Nova República"(IV), em 1985, mostra já uma compreensão de que a ciência é uma prática humana, social e, portanto, deve sofrer críticas, aprimorar seus argumentos, imiscuir-se na vida do país e contribuir para sua trans- 
formação. A ciência deve estar comprometida com as causas mais candentes da sociedade.

Certamente esse foi o primeiro CONBRACE no qual se abriu espaço para um fértil debate de concepções de EF escolar, de Esporte, de Lazer; um primeiro momento em que esses objetos foram amplamente problematizados pelo aporte das ciências humanas. Teve-se, no Brasil, um debate acadêmico que ficou para sempre na memória dos que lá estiveram. Naquele CONBRACE de 1985, o esporte emergiu como um fenômeno também social, histórico, que explicava sociedades.

O corpo era também uma inscrição viva, um texto no qual as sociedades escrevem sua história conforme antropólogos, sociólogos, historiadores e filósofos já afirmavam havia décadas. Talvez naquele momento tenhamos compreendido em profundidade algo já dado desde o século XVIII e que é alargado por Rousseau, ou seja, que [...]" a arte da educação é, de algum modo, a arte de substituir um corpo por outro". ${ }^{30}$

A EF escolar, por exemplo, poderia construir-se a partir de outros modelos e não mais apenas a partir do referencial da aprendizagem motora, do desenvolvimento motor e da psicomotricidade. A ginástica, o jogo, os esportes, a dança, deste modo, ganharam a possibilidade de ser problematizados como conhecimentos clássicos que se ensinam na escola para crianças e jovens; os conhecimentos da EF escolar não seriam exclusivos para meninos e para meninas, muito menos para faixas etárias; esta era apenas uma abordagem, não mais a única possível. De um mesmo modo, o conhecimento não necessitaria mais ser definido e autorizado por médicos e a EF escolar não precisaria mais ser, exclusivamente, uma questão médica, ela poderia ser uma questão pedagógica. Neste caso, cada conhecimento a ser ensinado necessitava de sua história. Esta história deveria ser escrita...inaugurava-se, assim, uma compreensão de que não existe uma verdade sobre a EF escolar, e que seus conteúdos, métodos, objetivos são históricos, re-significam-se... muitas concepções são possíveis e cada uma delas revela interesses, ambições e receios daqueles que as formulam, dos lugares sociais e

\footnotetext{
$30 \mathrm{~J}$. Verdier, "Cours d'éducation à 1'usage des élèves", apud Georges Vigarello. IInnocular para proteger: a inoculação da varíola e a imagem do corpo. Revista Projeto História, EDUC/PUC-SP, dez.,2002, p.22.
}

Movimento Porto Alegre, v.9, n. 3, p.125-147, set./dez. de 2003 
políticos que ocupam. O debate ainda foi tímido, mas foi seguro, e abriu espaço, tomou um lugar.

"A criança e o esporte no Brasil"(V), em 1987, realizado em Olinda, recupera o tema da criança, tema que já fora objeto do I CONBRACE em 1979, porém, o faz sob outras bases; o tema oficial questiona a ciência, assim como a sociedade na qual se faz ciência . Em seu editorial, indaga:

[...] Como refletir a criança e o esporte? De que criança estamos falando?[...] ou será que tivemos a humildade de refletir a criança no seu contexto... [marcado] pelo trabalho precoce, pela prostituição aos milhares já aos 10,12, 15 anos, como sobrevivência, pelo vício, enfim? A que esporte estamos nos referindo? Poderá o esporte, à margem das estruturas e práticas político- sociais dominantes [...] constituir-se como remédio para todos os males? ${ }^{31}$

Os debates lá realizados, em uma multiplicidade de mesas, conferências, seminários, painéis e temas livres, buscaram respostas a estas e outras indagações, chamando a atenção para o fato de que a ciência é sempre comprometida e movida por interesses múltiplos. Também naquele CONBRACE se fez algo vinculado à cultura local, desde a capa de seus anais, lindamente ilustrada com a pintura primitiva $O$ recreio na escola, feita por Amaro Francisco, artista pernambucano, até a programação cultural.

Em 1989, Brasília foi a sede do VI CONBRACE, evento que foi marcante para os rumos do $\mathrm{CBCE}$, já que seu tema teve abrangência internacional: "Esporte e mudança na América Latina", um tema que se coadunava com um momento político do continente no qual as ditaduras caíam e governos democráticos, junto com sociedades marcadas pelos anos de ditadura, ensaiavam uma mudança de práticas. Com a EF/CE não foi diferente, pois elas eram parte da sociedade e parte de suas conquistas e misérias. Esse evento foi importante para a continuidade de um processo de crítica iniciado de modo mais marcante em 1985.

Inúmeras indagações, disputas, revezes e futuras conquistas do CBCE foram iniciadas ali e foram aqueles embates acadêmicos e políticos, de rumos de política cientifica para o CBCE, que deram o impulso para que se desse início ao debate do próprio conhecimento que se produzia no âmbito da EF/CE no Brasil, do CBCE como instituição científica e de seu lugar neste debate.

31 "Editorial", Revista Brasileira de Ciências do Esporte, vol. 9, n 1, 1987.

Movimento Porto Alegre, v.9, n. 3, p.125-147, set./dez. de 2003 
Isto permitiu a emergência, já respaldada por pesquisas que refletiam sobre a produção do conhecimento em EF/CE a partir de seus programas de pós-graduação, do tema oficial do CONBRACE de 1991, (o VII), realizado em Uberlândia, cujo tema foi "Produção e veiculação do conhecimento na Educação Física, Esporte e Lazer no Brasil: análise e perspectivas". Tanto as conferências, simpósios, quanto as mesas redondas, painéis e comunicações coordenadas trataram da produção e veiculação do conhecimento em diferentes âmbitos como a escola, o lazer, o esporte, a formação profissional, a imprensa, os partidos políticos, o deficiente e a pós-graduação... Também nesse evento houve uma presença bastante equilibrada entre perspectivas que problematizavam a $\mathrm{EF} / \mathrm{CE}$ a partir das ciências naturais e das ciências humanas.

O acúmulo de discussões neste CONBRACE, acrescido do debate no âmbito mesmo da pós-graduação em outros fóruns, fez o CBCE indagar, em 1993, qual era a ciência que se produzia, e o tema do VIII CONBRACE, realizado em Belém do Pará, ganhou o seguinte título: "Que ciência é essa? Memória e tendências", título que leva em consideração principalmente as condições históricas de desenvolvimento da pesquisa na EF no Brasil.

Muitos dos debates lá realizados em meio à comemoração dos 15 anos da entidade produziram a necessidade de um aprofundamento no que concerne ao conhecimento e ao modo de produzi-lo; era necessário pensar a EF/CE como constituída por objetos que exigiam abordagens interdisciplinares, desejo antigo do CBCE de ser multiprofissional, conforme afirmara um de seus presidentes em $1981^{32}$. A EF/CE era constituída pelas ciências naturais e pelas ciências humanas; abordagens de campos distintos geram problemas e objetos distintos, respostas distintas. $\mathrm{O}$ CBCE necessitava de maior rigor, necessitava de grupos de trabalho, necessitava de textos escritos para o debate em seus eventos. O IX CONBRACE, realizado em Vitória, no ano de 1995, inaugura então uma terceira fase na vida da entidade.

Seu tema foi "Interdisciplinaridade, Ciência e Pedagogia", tema que buscou demarcar com mais clareza que a EF/CE necessitava ser tratada interdisciplinarmente. Também naquele evento se tomou a iniciativa de solicitar um texto completo no momento da inscrição para os trabalhos a serem apresentados

32 Dr. Cláudio Gil, em artigo publicado naRevista Brasileira de Ciências do Esporte número especial - 20 anos do CBCE, set. 1998. 
nos CONBRACEs em suas diferentes sessões. Em seu editorial podese ler:

/... Esta atitude esteve referenciada no entendimento de que a exigência do texto seria um elemento interessante para tentarmos qualificar este espaço de veiculação e discussão de conhecimento [...] estamos produzindo conhecimento e qualificando nossa intervenção enquanto entidade científica. ${ }^{33}$

Nesse CONBRACE o modo de organização dos trabalhos é modificado e amplia-se a compreensão de que a organização por temáticas permite um maior aprofundamento nas discussões. Num certo sentido, o que ocorreu em Vitória foi embrionário para o que ocorreria no CONBRACE seguinte, realizado em Goiânia, dois anos mais tarde. O CBCE consolidava uma compreensão de que em uma entidade científica o trabalho deveria ser organizado em grupos de trabalho que traduzissem problemáticas importantes para a área e, naquele momento, pareceu aos seus dirigentes e secretarias que a organização dos trabalhos por grupos iniciados em Vitória deveria constituir os Grupos de Trabalho Temáticos (GTTs).

Um delicado e denso trabalho então é iniciado naquele momento com a diretoria eleita em Vitória, no que concerne à construção dos chamados GTTs, que foram, naquele momento, configurados em número de $11^{34}$ e que revelavam, naquele momento, as problemáticas mais candentes para a EF/CE.

Deste modo, o X CONBRACE, realizado em Goiânia no ano de 1997, teve como tema oficial 'As renovações, modismos e interesses", tema que permitiu um debate mais profundo acerca, por exemplo, dos impactos dos ordenamentos legais, tanto para a EF escolar, quanto para o esporte nacional, ordenamentos que ainda requeriam pareceres para serem seguidos.

Esse CONBRACE foi único em sua organização e foi um marco na configuração do CBCE e de seus CONBRACEs, que, desde então, foram estruturados em GTTs e estes, em espaços

\footnotetext{
33 "Editorial", Revista Brasileira de Ciências do Esporte, vol. 17, n. 1,1995.

34 GTT1-Educação Física/Esportes e Escola; GTT2-Educação Física/Esporte e Políticas Públicas; GTT3-Educação Física/Esporte, Comunicação e Mídia; GTT4- Educação Física/Esporte e Processo Ensino Aprendizagem; GTT5-Educação Física/Esporte e Formação profissional/ Campo de Trabalho; GTT 6-Educação Física/Esporte e Recreação/Lazer; GTT7- Educação Física/Esporte e Saúde; GTT8-Educação Física/ Esporte e Rendimento de Alto Nível; GTT9- Educação Física/Esporte e Portadores de Necessidades Especiais; GTT 10- Educação Física/Esporte e Grupos/Movimentos Sociais; GTT 11- Educação Física/Esporte e Epistemologia.
}

Movimento Porto Alegre, v.9, n. 3, p.125-147, set./dez. de 2003 
de consulta da entidade para que pudesse ter, cada vez mais, uma Intervenção qualificada em temas relativos à $\mathrm{EF} / \mathrm{CE}$ no Brasil. Essa proposta, contudo, não ocorreu sem conflitos, aliás, conflitos presentes até hoje, mas afirmou o CONBRACE como um lugar do debate acadêmico, das diferenças que não devem ser tratadas como desigualdades, das múltiplas concepções que resultam em múltiplos problemas a serem pesquisados. Os próprios GTTs pensados naquele momento já se modificaram e, certamente, continuarão este processo que é mesmo aquele do conhecimento e do modo de se olhar para ele.

Se o tema do VII (1991), VIII (1993) e IX CONBRACE (1995) contemplou reflexões acerca do conhecimento, do que é ciência, o XI (1999) e o XII (2001) CONBRACEs, realizados respectivamente em Florianópolis e Caxambu, apresentam temas bastante amplos e ao mesmo tempo provocativos:"EF/CE: intervenção e conhecimento" e "Sociedade, ciência e ética: desafios para a Educação Física".

Entre o tempo de realização desses dois últimos CONBRACEs, GTTs foram extintos e outros tomaram seus lugares; a intervenção qualificada do $\mathrm{CBCE}$ em diferentes fóruns da sociedade brasileira que dizem respeito a problemáticas da $\mathrm{EF} / \mathrm{CE}$ foram alargados e sua presença na SBPC está consolidada como entidade científica em igualdade com as demais. Além de uma relação densa com as problemáticas que têm envolvido desde o financiamento da pesquisa científica em EF/CE até assessorias ao Conselho Nacional de Educação (CNE), assim como participação nos debates que têm ocorrido em torno dos ordenamentos legais da profissão.

Para finalizar, queria ressaltar que é mais especificamente na década de 90 que a pesquisa histórica em EF começa a reivindicar espaço institucional no âmbito da entidade e começa também a apresentar críticas ao modo como se começou a fazer pesquisa histórica no início dos anos 80 . O fim da década de 90, de um certo modo, revela a evidente preocupação com as fontes que são utilizadas; com o modo como estas fontes são indagadas; afirma-se a idéia de que existem histórias da EF, no plural.

Objetos esquecidos nos cantos da memória, pouco tratados, emergem e recebem atenção. A própria EF escolar é historicizada; a riqueza das histórias regionais surge com muito vigor. Não somos apenas aquilo que aconteceu no Rio de Janeiro; a história 
da EF no Brasil é maior, não é um mero reflexo da Corte e antiga capital da República, e, embora existam influências, estas não são dominantes e nem excluem idiossincrasias. Estas histórias regionais e de particularidades regionais constroem-se de modo diferente, com fontes muito especiais... com a história oral, com arquivos de família, com a tentativa sempre fugaz da história de re-constituir o longínquo, aquilo que foi um dia um complexo vivo de significações e que hoje nos chega por vestígios, fragmentos; constroem-se com a compreensão de que as fontes não falam por si, mas que necessitam ser interrogadas pelo pesquisador; que a própria idéia de fonte e da sua importância para a pesquisa é uma elaboração lenta e densa de cruzamentos, de reverberações entre aquilo que se quer conhecer em um tempo que já não é mais o nosso, uma sensibilidade, sobretudo, que não é a nossa. Talvez neste momento possamos pensar que não há dados naturalmente organizados mas...historicamente construídos. E qual seria então a tarefa da história senão a de [...]"restituir aos indivíduos o sentido de suas histórias singulares, irredutíveis umas às outras, a consciência das diferenças que particularizam as sociedades, os territórios, os grupos"?, ${ }^{35}$ pergunta Philippe Aries. Assim, surge a necessidade de não apenas tornar sempre mais complexos gestos e práticas que se constituem em objeto de estudo histórico para a EF/CE e que são aparentemente simples e até banais mas, ao mesmo tempo, desconfiar de nossos próprios esquemas representativos, ou seja, de homens e mulheres que pertencem à sociedade de hoje. ${ }^{36}$

Cuerpo, educación física y muchas historias
Resumen: Este articulo concibe al "Colégio Brasileiro
de Ciências do Esporte (CBCE)" como un lugar posible
para la memoria que revela, a pesar de su corta existencia
-25 años-la emergencia y la visibilidad de las muchas
historias de la Educación Física y las Ciencias del De-
porte en Brasil. Este tema será tratado a partir de las
transformaciones en los problemas, objetos y abordajes
desarrollados desde esta institución. Palabras-
clave: Cuerpo, CBCE, Historia de la Educación
Física.

35 Philippe Aries, O tempo da história, 1989, p.17.

36 Cf. Georges Vigarello, op.cit, 2003, pp. 21-30.

Movimento Porto Alegre, v.9, n. 3, p.125-147, set./dez. de 2003 
Body, Physical Education: multiples histories Abstract: This paper conceives the "Colégio Brasileiro de Ciências do Esporte (CBCE)" as a place for memory, related with the emergence and visibility of the History of Physical Education and Sports Sciences in Brazil. This issue will be discussed taking into account the transformations in the problems, objects and scopes developed by this institution trough time. Keywords: Body, CBCE, History of Physical Education.

\section{Referências}

ARIES, Philippe. O tempo da história. Rio de Janeiro: Francisco Alves, 1989. BLOCH, Marc. $5^{\text {a }}$. ed. introdução à história.[s. I.]: Mira- Cintra, 1987. CONRAD, Joseph. Linha de sombra: uma confissão: "mercadores do meu eterno apreço". Rio de Janeiro: O Globo/São Paulo: Folha de São Paulo, 2003.

GOELLNER, Silvana Vilodre. Be/a, Maternal e Feminina: imagens da mulher na Revista Educação Physica. ljuí: Unijuí, 2003.

LINHALES, Meily A . A trajetória política do esporte no Brasil: interesses envolvidos, setores excluídos. 1996. Dissertação(Mestrado em CiéVncia Política). Belo Horizonte: FAFICH/UFMG.

OLIVEIRA, Marcus Aurélio Taborda. Educação Física escolar e ditadura militar no Brasil (1968-1984): entre a adesão e a resistência. Bragança Paulista: EDUSF-2003.

PAIVA, Fernanda Simone. Educação Física/Ciências do Esporte: resgate e perspectiva na luta dos sentidos dentro do CBCE. 1993. Dissertação (Mestrado em Educação Física). Rio de Janeiro, Universidade Gama Filho.

PAIVA, Fernanda Simone. Ciência e poder simbólico no Colégio Brasileiro de Ciências do Esporte. Vitória:CEFD/UFES, 1994.

SILVA, Ana Márcia. Corpo, ciência e mercado: reflexões acerca de um novo arquétipo da felicidade. Campinas: Autores associados/Editora da UFSC, 2001. STAROBINKI, Jean. A Literatura. In LE GOFF Jacques e NORA, Pierre. (orgs.) 3a. Ed. História: novas abordagens. Rio de Janeiro: Francisco Alves, 1988.

SOARES, Carmen. Educação Física: raízes européias e Brasil. $2^{\mathrm{a}}$. ed. Campinas: Autores Associados, 2001.

SOARES, Carmen. Imagens da Educação no Corpo: estudo a partir da ginástica francesa no século XIX. $2^{\text {a }}$.ed.Campinas: Autores Associados, 2002.

SANT'ANNA, Denise Bernuzzi de. O prazer justificado: história e lazer (São Paulo, 1969/1979). São Paulo: Marco Zero/CNPq, 1992.

Movimento Porto Alegre, v.9, n. 3, p.125-147, set./dez. de 2003 
TERRA, Vinícius, Demarchi. Pedaços do tempo, gestos partidos: memórias do corpo na fotografia de Etienne-Jules Marey. 2002. Dissertação(Mestrado em Educação), Campinas, Faculdade de Educação/UNICAMP

VAGO, Tarcísio Mauro. Cultura Escolar, cultivo de corpos: educação physica e gymnástica como práticas constitutivas dos corpos de crianças no ensino público primário de Belo horizonte (1906-1920). Bragança Paulista: EDUSF- 2002.

VIGARELLO, Gorges. Le corps redressé: Histoire d'un pouvoir pédagogique. Paris, Jean Pierre Delarge, 1978

VIGARELLO, Gorges. Du jeu anclen au show sportif: la naissance d'un mythe. Paris: Seuil, 2002.

\section{Periódicos}

Revista Brasileira de Ciências do Esporte. Número Especial-20 anos CBCE, set. 1998.

Revista Brasileira de Ciências do Esporte, vol. 1, n. 1, 1979.

Revista Brasileira de Ciências do Esporte. Suplemento n. 1, set. 1981.

Revista Brasileira de Ciências do Esporte, vol. 5, n. 1, set. 1983.

Revista Brasileira de Ciências do Esporte, vol. 7, n. 1, set. 1985

Revista Brasileira de Ciências do Esporte, vol. 9, n. 1, set. 1987

Revista Brasileira de Ciências do esporte, vol. 11, n. 1, set. 1989.

Revista Brasileira de Ciências do Esporte, vol. 13, n. 1, set. 1991

Revista Brasileira de Ciências do Esporte, vol. 14, n. 3, set. 1993.

Revista Brasileira de Ciências do Esporte, vol. 17, n. 1, set. 1995.

Revista Brasileira de Ciências do Esporte, vol. 19, n. 1, set, 1997.

Revista Brasileira de Ciências do Esporte, vol. 21, n. 1, set, 1999.

Revista Pro-Posições. Campinas: Faculdade de Educação/U NI CAMR v. 14, n 2(41) Dossiê "Visibilidade do Corpo", 2003.

Revista Educação e Realidade. Porto Alegre: Faculdade de Educação/Universidade Federal do Rio Grande do Sul. V. 25, n. 2. Produção do Corpo. 2000.

Revista Projeto História.São Paulo:EDUC/PUC-SR "Corpo e Cultura", n 25 dez., 2002.

Educarem Revista. Curitiba:Edit. da UFPR, n.16, "Dossiê corporalidade e educação", 2000.

Recebido em: 10/11/2003

Aprovado em: 03/12/2003

Carmen Lúcia Soares

Rua Padre Vieira, 1080, apto 22

Campinas -SP

13015-301

carmenls@unicamp.br

Movimento Porto Alegre, v.9, n. 3, p.125-147, set./dez. de 2003 